\title{
MOTIVASI DAN PERSEPSI WISATAWAN MANCANEGARA BERWISATA ALAM TREKKING MOUNTAIN DI TAMAN WISATA ALAM GUNUNG BATUR BUKIT PAYANG
}

\author{
I Kadek Witarsana \\ Luh Gede Leli Kusuma Dewi \\ Ni Gusti Ayu Susrami Dewi \\ Email : witarsanakadek@gmail.com \\ PS. S1 Industri Perjalanan Wisata \\ Fakultas Pariwisata UNUD
}

\begin{abstract}
Trekking mountain as one of foreign tourism activities in Mount Batur became more popular now days. The beauty of the sunrise from the top of the mountain become an attraction for foreign tourists to conduct trekking mountain in the Natural Tourism Park of Mount Batur Hill Payang. Therefore, the purpose of this study was to determine the motivation and perception of foreign tourists to do trekking mountain in the Natural Tourism Park of Mount Batur Hill Payang. This study using purposive sampling by distributing questionnaires to 150 foreign tourists as respondents. Some techniques were used such as: observation, interview, questionnaire, literature, and documentation. And for data analysis used qualitative and quantitative analysis. The results of this study showed that motivation of push factor affects tourists do trekking in Mount Batur are to see the sights at the top of the mountain in order to feel relaxed, to get a different atmosphere, and doing something new and different. While the motivation of pull factor that attracts tourists for trekking mountain Batur are the stunning natural environment, the presence of wildlife, as well as the atmosphere and climate of Mount Batur. Perception rating indicates that the services provided by trekking guide has been very good, but the rating was less about the cleanliness of the toilets and track trekking in the Natural Tourism Park of Mount Batur Hill Payang.
\end{abstract}

Keywords: Motivation, Perception, Nature Tourism, Trekking Mountain.

\section{PENDAHULUAN}

Kintamani terkenal dengan keindahan pemandangan alam pegunungan yang dapat dilihat dan dinikmati oleh setiap wisatawan yang mengunjunginya. Wisatawan yang mengunjungi Kawasan Kintamani dapat menikmati keindahan alam pegunungan melalui atas bukit sembari menyantap makanan di setiap restoran dengan pemandangan yang langsung mengarah ke Taman Wisata Alam Gunung Batur Bukit Payang dan Danau Batur. Keindahan panorama ini mampu menjadi daya tarik bagi wisatawan baik nusantara mauun mancanegara. Selain keindahan dari Gunung Batur, salah satu aktivitas wisata yang saat ini banyak digemari oleh wisatawan mancanegara adalah trekking mountain.

Kegiatan trekking mountain banyak dilakukan oleh wisatawan mancanegara di Taman Wisata Alam Gunung Batur Bukit Payang. Hal ini terlihat dari jumlah wisatawan yang melakukan trekking mountain Batur yang semakin meningkat dapat dilihat pada Tabel 1. Dari Tabel 1 dapat dilihat pertumbuhan jumlah kunjungan wisatawan yang melakukan kegiatan trekking mountain di Taman Wisata Alam Gunung Batur Bukit Payang mengalami peningkatan selama empat tahun terakhir. Dimana pada tahun 2012 jumlah wisatawan mancanegara yang melakukan trekking mountain meningkat sebesar $16,7 \%$ dari tahun sebelumnya. Peningkatan ini juga berlanjut ke 
tahun berikutnya yaitu pada tahun 2013 meningkat sebesar $26,7 \%$ dan tahun 2014 meningkat sebesar $34,2 \%$. Jumlah wisatawan yang melakukan trekking mountain juga meningkat pada tahun 2015 sebesar 12,1\%, walaupun peningkatan ini tidak sebesar tahun sebelumnya. Namun secara keseluruhan, jumlah wisatawan yang melakukan trekking mountain, mengalami peningkatan setiap tahunnya. Taman Wisata Alam Gunung Batur Bukit Payang telah diakui oleh UNESCO sebagai Global Geopark (Taman Bumi) pertama yang ada di Indonesia pada tahun 2012. Geopark atau disebut taman bumi merupakan sebuah kawasan atau situs warisan geologi (geological heritages) yang mempunyai nilai ekologi dan warisan budaya (cultural heritages) dan berfungsi sebagai daerah konservasi, edukasi, dan perkembangan berkelanjutan.

Tabel 1. Jumlah Wisatawan Mancanegara Yang Melakukan Trekking Mountain di Taman Wisata Alam Gunung Batur Bukit Payang

\begin{tabular}{|c|c|c|}
\hline Tahun & Jumlah Kunjungan & $\begin{array}{l}\text { Pertumbuhan } \\
(\%)\end{array}$ \\
\hline 2011 & 25.113 & \\
\hline 2012 & 29.300 & 16,7 \\
\hline 2013 & 37.122 & 26,7 \\
\hline 2014 & 49.818 & 34,2 \\
\hline 2015 & 55.862 & 12,1 \\
\hline
\end{tabular}

Sumber: Dinas Pariwisata Dan Kebudayaan Kabupaten Bangli, 2016.

Semakin meningkatnya kunjungan wisatawan setiap tahunnya menjadi fenomena menarik untuk melakukan studi mengenai motivasi dan persepsi wisatawan mancanegara berwisata alam trekking mountain di Taman Wisata Alam Gunung Batur Bukit Payang. Penelitian ini penting dilakukan karena dengan mengetahui motivasi dari wisatawan mancanegara melakukan trekking mountain di Taman Wisata Alam Gunung Batur Bukit Payang dan persepsi wisatawan mancanegara terhadap trekking mountain di Taman Wisata Alam Gunung Batur Bukit Payang dapat dijadikan informasi dan acuan bagi pihak pengelola dalam memberi pelayanan sehingga dapat memenuhi kebutuhan serta harapan dari wisatawan mancanegara yang melakukan trekking mountain di Taman Wisata Alam Gunung Batur Bukit Payang.

\section{METODE}

Lokasi penelitian di Taman Wisata Alam Gunung Batur Bukit Payang yang terletak di Kecamatan Kintamani, Kabupaten Bangli, Provinsi Bali. Sedangkan, definisi operasional variabel yang digunakan terdiri dari 2 variabel, yaitu motivasi dan persepsi. Variabel motivasi ditinjau berdasarkan teori dari Crompton, Dann, Mannell and Iso-Ahola dan Krippendorf dalam (Wall \& Mathieson, 2006) yang berpendapat bahwa, motivasi dapat dikatagorikan menjadi dua dimensi, pertama yaitu: faktor pendorong (push factor) dan kedua, faktor penarik (pull factor). Sedangkan variabel persepsi ditinjau berdasarkan Cahya Murti dan Sujali (2013) yang menyatakan bahwa seseorang, kelompok orang atau wisatawan dapat mengasilkan persepsi dengan melakukan pengukuran terhadap kejelasan objek dan pelayanan yang terdapat dalam objek berdasarkan dua aspek, yaitu: fisik dan non fisik. Jenis data yang digunakan dalam penelitian ini adalah data kualitatif dan data kuantitatif. Sedangkan teknik pengumpulan data yang dipergunakan adalah observasi, wawancara tak-terstruktur, kuesioner, studi kepustakaan, dan dokumentasi. Teknik penentuan sampel dilakukan dengan purposive sampling yaitu teknik penentuan sampel dengan pertimbangan tertentu (Sugiyono, 2015) dan pengambilan sampel menggunakan accidental sampling yaitu teknik sampel dilakukan apabila pemilihan anggota sampelnya dilakukan terhadap orang atau benda yang kebetulan ada atau dijumpai (Usman, 2006). Kriteria sampel dalam penelitian ini adalah wisatawan mancanegara yang ditemui secara tidak disengaja di lokasi penelitian setelah melakukan trekking mountain dengan jumlah sampel yang diambil sebanyak 150 responden. Dan teknik analisis data yang dipergunakan adalah teknik analisis data deskriptif kualitatif dan deskriptif kuantitatif.

\section{HASIL}

Kawasan Taman Wisata Alam Gunung Batur Bukit Payang secara geografis terletak diantara $8^{\circ} 13^{\prime} 32^{\prime \prime}-8^{\circ} 16^{\prime} 40^{\prime \prime}$ Lintang Selatan 
dan $115^{\circ} 20^{\prime} 28^{\prime \prime}-115^{\circ} 24^{\prime} 1^{\prime \prime}$ Bujur Timur, dengan ketinggian puncak $\pm 1.717 \mathrm{mdpl}$. Secara administratif, terletak di Kecamatan Kintamani, Kabupaten Bangli, Provinsi Bali. Potensi wisata di Taman Wisata Alam Gunung Batur Bukit Payang adalah trekking, pendakian Gunung Batur, bersepeda gunung, wisata religi/budaya, camping, fotografi, wisata kesehatan, wisata Geopark, pemandian air panas Toya Bungkah. Trekking mountain merupakan kegiatan atau aktivitas yang dilakukan dengan berjalan kaki melewati jalur yang telah tersedia dan melakukan pendakian gunung. Rute atau jalur yang harus dilewati saat melakukan trekking mountain di Taman Wisata Alam Gunung Batur Bukit Payang adalah start point dimulai dari kantor Perhimpunan Pramuwisata Pendakian Gunung Batur (PPPGB) yang berada di samping Pura Jati Batur. Kemudian berjalan melewati jalur Pura Pasar Agung, lintasan pertama ini masih jalan yang landai. Setelah mengikuti jalur jalan yang landai dan mulai sedikit menanjak kurang lebih sekitar 1 jam perjalanan, maka akan tiba di jalur berikutnya yaitu jalur bebatuan yang sedikit licin dan menanjak di dekat bangunan pura menuju pos pertama. Setelah melewati pos pertama yang juga merupakan tempat peristirahatan, selanjutnya jalur yang harus dilalui adalah jalur bebatuan dan jalan berpasir yang terus menanjak hingga sampai di puncak Gunung Batur. Waktu yang diperlukan hingga tiba di puncak Gunung Batur adalah sekitar 2 jam perjalanan dan pendakian gunung dengan jarak sekitar $4 \mathrm{Km}$.

Berdasarkan dari hasil penyebaran kuesioner terhadap 150 responden wisatawan mancanegara yang melakukan trekking mountain di Taman Wisata Alam Gunung Batur Bukit Payang diketahui bahwa berdasarkan jenis kelamin adalah wisatawan perempuan sebanyak $54,6 \%$ dan wisatawan laki-laki sebanyak 45,3\%, berdasarkan usia, wisatawan yang berusia 21-30 tahun mendominasi sebesar 78\%, berdasarkan daerah asal wisatawan, dari benua Eropa sebanyak 80,7\%, dari benua Amerika sebanyak 12,7\%, dari benua Australia sebanyak 6\%, dan dari benua Asia sebanyak $0,6 \%$, berdasarkan pekerjaan adalah wisatawan sebagai karyawan sebesar $62,7 \%$, sebagai pelajar sebesar $30 \%$, dan sisanya sebagai pengusaha serta profesi lainnya. Berdasarkan teman perjalanan, didominasi bersama dengan sahabat sebesar $63,9 \%$, bersama grup sebesar
$26,3 \%$, sisanya $9,8 \%$ bersama keluarga dan seorang diri, berdasarkan sumber informasi adalah dari sumber internet (sosial media) sebesar 36,6\%, dari rekomendasi teman sebesar $26,8 \%$, dari buku petunjuk wisata sebesar $25,4 \%$, sisanya sebesar $11,2 \%$ dari agen perjalanan, majalah dan sumber lainnya, berdasarkan kendaraan, lebih banyak menggunakan mobil sebesar 95,4\%, menggunakan bus (ELF) sebesar 3,3\%, dan menggunakan motor sebesar $1,3 \%$.

Motivasi yang mendorong (push factor) wisatawan untuk melakukan trekking mountain di Taman Wisata Alam Gunung Batur Bukit Payang dapat dilihat pada Tabel 2.

Tabel 2. Motivasi Yang Mendorong (Push Factor) Wisatawan Mancanegara

\begin{tabular}{llcc}
\hline No & Pernyataan & $\begin{array}{l}\text { Total } \\
\text { Skor }\end{array}$ & $\begin{array}{l}\text { Rata- } \\
\text { rata }\end{array}$ \\
\hline 1 & $\begin{array}{l}\text { Motivasi untuk } \\
\text { mendapat suasana } \\
\text { yang berbeda }\end{array}$ & 641 & 4,27 \\
\hline 2 & $\begin{array}{l}\text { Motivasi untuk } \\
\text { melakukan hal yang } \\
\text { baru dan berbeda } \\
\text { seperti trekking } \\
\text { mountain }\end{array}$ & 631 & 4,21 \\
\hline 3 & $\begin{array}{l}\text { Motivasi untuk } \\
\text { melakukan trekking } \\
\text { mountain agar merasa } \\
\text { santai saat di puncak } \\
\text { gunung }\end{array}$ & & \\
\hline Total & & \\
\hline Rata-rata & & \\
\hline Sata & & \\
\hline
\end{tabular}

Sumber: Hasil penelitian, 2016.

Diketahui dari Tabel 2, motivasi yang mendorong (push factor) wisatawan untuk melakukan trekking mountain di Taman Wisata Alam Gunung Batur Bukit Payang, adalah: 1) melakukan trekking mountain untuk mendapat suasana yang berbeda dengan skor 641 dan rata-rata 4,27 termasuk kategori sangat setuju. 2) melakukan hal yang baru dan berbeda dengan total skor 631 dan rata-rata 4,21 termasuk kategori sangat setuju. 3) melakukan trekking mountain dan melihat pemandangan di puncak gunung agar merasa santai dengan total skor 644 dan rata-rata 4,29 termasuk kategori sangat setuju.

Sedangkan motivasi yang menarik (pull factor) wisatawan untuk melakukan trekking 
mountain di Taman Wisata Alam Gunung Batur Bukit Payang dapat dilihat pada Tabel 3.

Tabel 3. Motivasi Yang Menarik (Pull Factor) Wisatawan Mancanegara

\begin{tabular}{clrc}
\hline No & Pernyataan & $\begin{array}{l}\text { Total } \\
\text { Skor }\end{array}$ & $\begin{array}{l}\text { Rata- } \\
\text { rata }\end{array}$ \\
\hline 1 & $\begin{array}{l}\text { Suasana dan iklim } \\
\text { yang bagus }\end{array}$ & 639 & 4,26 \\
\hline 2 & $\begin{array}{l}\text { Lingkungan dan } \\
\text { pemandangan alam } \\
\text { yang mempesona }\end{array}$ & 690 & 4,60 \\
\hline 3 & Keberadaan satwa liar & 666 & 4,44 \\
\hline & $\quad$ Total & & 13,30 \\
\hline & Rata-rata & 4,43 \\
\hline
\end{tabular}

Sumber: Hasil penelitian, 2016.

Diketahui dari Tabel 3, motivasi yang menarik (pull factor) wisatawan untuk melakukan trekking mountain di Taman Wisata Alam Gunung Batur Bukit Payang, adalah: adalah 1) suasana dan iklim di Gunung Batur sangat bagus mendapat total skor 639 dan rata-rata 4,26 termasuk kategori sangat setuju. 2) Lingkungan alam di puncak Gunung Batur sangat bagus memperoleh total skor 690 dan rata-rata 4,60 termasuk kategori sangat setuju. Dan 3) menyukai keberadaan satwa liar di gunung mendapat total skor 666 dan ratarata 4,44 termasuk dalam kategori sangat setuju.

Adapun persepsi dari wisatawan mancanegara terhadap trekking mountain di Taman Wisata Alam Gunung Batur Bukit Payang dari segi fisk dan non fisik. Persepsi wisatawan terhadap trekking mountain Batur dari segi fisik, dapat dilihat pada Tabel 4.

Tabel 4. Persepsi Wisatawan Mancanegara dari Segi Fisik

\begin{tabular}{llcc}
\hline No & Pernyataan & $\begin{array}{c}\text { Total } \\
\text { Skor }\end{array}$ & $\begin{array}{c}\text { Rata- } \\
\text { rata }\end{array}$ \\
\hline 1 & $\begin{array}{l}\text { Terdapat tempat } \\
\text { parkir yang luas dan } \\
\text { memadai }\end{array}$ & 638 & 4,25 \\
\hline 2 & $\begin{array}{l}\text { Terdapat penjual } \\
\text { makanan dan } \\
\text { minuman }\end{array}$ & 632 & 4,21 \\
\hline 3 & $\begin{array}{l}\text { Trekking di TWA } \\
\text { Gunung Batur Bukit }\end{array}$ & 501 & 3,34 \\
\hline
\end{tabular}

\begin{tabular}{|c|c|c|c|}
\hline & $\begin{array}{l}\text { Payang bersih dari } \\
\text { sampah }\end{array}$ & & \\
\hline 4 & $\begin{array}{l}\text { Toilet umum yang } \\
\text { bersih di TWA } \\
\text { Gunung Batur Bukit } \\
\text { Payang }\end{array}$ & 327 & 2,18 \\
\hline 5 & $\begin{array}{l}\text { Tidak ada kehilangan } \\
\text { barang berharga pada } \\
\text { saat trekking mountain }\end{array}$ & 671 & 4,47 \\
\hline 6 & $\begin{array}{l}\text { Naik dan turun } \\
\text { gunung saat trekking } \\
\text { sangat aman }\end{array}$ & 525 & 3,50 \\
\hline 7 & $\begin{array}{l}\text { Jalur trekking } \\
\text { mountain tidak terlalu } \\
\text { sulit dan mudah } \\
\text { dilewati }\end{array}$ & 517 & 3,44 \\
\hline Tot & & & 25,39 \\
\hline & -rata & & 3,62 \\
\hline
\end{tabular}

Sumber: Hasil penelitian, 2016.

Diketahui pada Tabel 4, wisatawan mancanegara menyatakan sangat setuju dengan tempat parkir yang luas dan memadai memberikan total skor 638 dengan rata-rata 4,25 . Wisatawan menyatakan sangat setuju terdapat penjual makanan di puncak dan di bawah dekat tempat parkir memperoleh total skor 632 dengan rata-rata 4,21. Wisatawan menyatakan cukup setuju terhadap kebersihan jalur trekking mendapat total skor 501 dengan rata-rata 3,34. Wisatawan menyatakan tidak setujua terhadap kebersihan toilet umum dengan total skor 327 dengan rata-rata 2,18. Wisatawan menyatakan sangat setuju terhadap keamanan dan tidak ada kehilangan barang berharga selama pendakian dengan total skor 671 dengan rata-rata 4,47.Wisatawan menyatakan setuju terhadap keamanan jalur trekking saat menaiki dan menuruni gunung mendapat total skor 525 dengan rata-rata 3,50. Dan wisatawan menyatakan setuju terhadap kemudahan saat melalui jalur trekking mountain Batur mendapat total skor 517 dengan rata-rata 3,44 .

Sedangkan persepsi wisatawan mancanegara terhadap trekking mountain Batur dari segi non fisik, dapat dilihat pada Tabel 5. 
Tabel 5. Persepsi Wisatawan Mancanegara Dari Segi Non Fisik

\begin{tabular}{|c|c|c|c|}
\hline No & Pernyataan & $\begin{array}{l}\text { Total } \\
\text { Skor }\end{array}$ & $\begin{array}{c}\text { Rata- } \\
\text { rata }\end{array}$ \\
\hline 1 & $\begin{array}{l}\text { Trekking guide sopan } \\
\text { dan ramah }\end{array}$ & 709 & 4,72 \\
\hline 2 & $\begin{array}{l}\text { Trekking guide } \\
\text { bertindak cepat dalam } \\
\text { menangani keluhan }\end{array}$ & 680 & 4,53 \\
\hline 3 & $\begin{array}{l}\text { Trekking guide } \\
\text { bertindak secara tepat } \\
\text { dan cermat dalam } \\
\text { mengatasi keluhan }\end{array}$ & 684 & 4,56 \\
\hline 4 & $\begin{array}{l}\text { Trekking guide } \\
\text { memberikan informasi } \\
\text { dengan jelas pada saat } \\
\text { trekking }\end{array}$ & 652 & 4,34 \\
\hline 5 & $\begin{array}{l}\text { Trekking guide } \\
\text { memberikan semangat } \\
\text { dan motivasi saat } \\
\text { mendaki }\end{array}$ & 677 & 4,51 \\
\hline 6 & $\begin{array}{l}\text { Trekking guide } \\
\text { memberikan } \\
\text { pertolongan pada saat } \\
\text { kesulitan mendaki }\end{array}$ & 720 & 4,80 \\
\hline \multicolumn{2}{|c|}{ Total } & & 27,46 \\
\hline \multicolumn{2}{|c|}{ Rata-rata } & & 4,57 \\
\hline
\end{tabular}

Sumber: Hasil penelitian, 2016.

Diketahui dari Tabel 5, bahwa wisatawan menyatakan sangat setuju terhadap kesopanan dan keramahan petugas dan trekking guide dengan total skor 709 dengan rata-rata 4,72.Wisatawan menyatakan sangat setuju terhadap kecepatan petugas dan trekking guide dalam menangani keluhan mendapat total skor 680 dengan rata-rata 4,53. Wisatawan menyatakan sangat setuju terhadap ketepatan dan kecermatan petugas maupun trekking guide dalam mengatasi keluhan mendapat total skor 684 dengan rata-rata 4,56. Wisatawan menyatakan sangat setuju terhadap kemampuan trekking guide dalam memberikan informasi dengan jelas mendapat total skor 652 dengan rata-rata 4,34. Wisatawan menyatakan sangat setuju terhadap kemampuan trekking guide dalam memberikan semangat dan motivasi selama pendakian mendapat total skor 677 dengan rata-rata 4,51. Dan wisatawan menyatakan sangat setuju terhadap kemampuan trekking guide dalam memberi bantuan dan pertolongan saat pendakian mendapat total skor 720 dengan rata-rata 4,80 .

\section{PEMBAHASAN}

Diketahui motivasi yang paling mempengaruhi atau motivasi yang memiliki skor tertinggi bagi wisatawan mancanegara untuk melakukan kegiatan trekking mountain di Taman Wisata Alam Gunung Batur Bukit Payang, diantaranya adalah: 1) untuk mendapatkan suasana yang berbeda saat melakukan trekking di Taman Wisata Alam Gunung Batur Bukit Payang, 2) melakukan suatu hal yang baru dan berbeda seperti: trekking mountain, dan 3) melakukan trekking mountain dan melihat pemandangan dari puncak gunung membuat pikiran menjadi tenang dan santai.

Dan motivasi yang menarik (pull factor) wisatawan mancanegara berwisata alam trekking mountain di Taman Wisata Alam Gunung Batur Bukit Payang antara lain: 1) suasana atau iklim Gunung Batur yang sangat bagus untuk mendaki, 2) keindahan alam pegunungan, dan 3) keberadaan satwa liar di puncak gunung.

Sedangkan hasil dari penelitian ini menunjukkan motivasi untuk melakukan kegiatan trekking mountain bersama anggota keluarga untuk memperkuat hubungan kekeluargaan (strengthening family bonds) dan motivasi untuk melakukan kegiatan trekking mountain untuk meningkatkan status atau derajat sosial (prestige) dirasa kurang mempengaruhi keinginan wisatawan mancanegara untuk melakukan aktivitas trekking mountain di Taman Wisata Alam Gunung Batur Bukit Payang. Hal ini didukung pula oleh karakteristik wisatawan yang menyatakan melakukan trekking mountain lebih dominan bersama sahabat ataupun grup dibandingkan dengan keluarga.

Diketahui persepsi wisatawan mancanegara terhadap trekking mountain di Taman Wisata Alam Gunung Batur Bukit Payang secara keseluruhan sudah baik dengan total skor rata-rata keseluruhan adalah 52,85 dengan rata-rata keseluruhan sebesar 4,06.

Tetapi terdapat persepsi yang kurang baik diberikan pada kebersihan jalur trekking dengan total skor 501 dan rata-rata 3,34 dan kebersihan toilet dengan total skor 327 dan rata-rata 2,18. Kebersihan jalur trekking yang 
dilalui wisatawan dirasa masih terdapat sampah, padahal pihak PPPGB telah meminta kepada para trekking guide yang mendampingi wisatawan saat pendakian untuk membawa sebuah kantong plastik agar memungut sampah plastik yang dilihat dan kegiatan gotong royong yang dilakukan oleh seluruh trekking guide di area parkir setelah selesai mendampingi wisatawan mendaki. Selain kebersihan jalur trekking, wisatawan mancanegara juga memberikan pendapat yang kurang baik terhadap kebersihan toilet umum. Berdasarkan pada hasil wawancara, pada dasarnya pihak PPPGB telah menugaskan dua orang petugas untuk selalu menjaga kebersihan toilet umum setiap harinya. Namun memang terlihat kebersihan toilet kurang dijaga karena fasilitas toilet umum masih dalam proses penataan dan terdapat rencana perbaruan toilet dari pihak PPPGB.

Persepsi wisatawan mancanegara dari segi non fisik menyatakan sudah sangat baik terhadap pelayanan yang diberikan oleh trekking guide saat melakukan trekking mountain di Taman Wisata Alam Gunung Batur Bukit Payang. Dimana persepsi wisatawan terhadap kesediaan trekking guide dalam memberikan bantuan atau pertolongan pada saat pendakian mendapat total skor tertinggi 720 dengan rata-rata 4,80 sedangkan persepsi wisatawan mancanegara terhadap kemampuan trekking guide dalam memberikan informasi dengan jelas saat pendakian mendapat skor terendah 652 dengan rata-rata 4,34. Hal tersebut dikarenakan terdapat beberapa trekking guide yang masih kurang memiliki pengalaman dan lemah dalam kemampuan berbahasa asing.

\section{SIMPULAN DAN SARAN \\ Simpulan}

Berdasarkan hasil penelitian yang dilakukan mengenai motivasi dan persepsi wisatawan mancanegara berwisata alam trekking mountain di Taman Wisata Alam Gunung Batur Bukit Payang, maka dapat disimpulkan bahwa :

1. Motivasi yang mendorong (push factor) wisatawan mancanegara untuk melakukan trekking mountain di Taman Wisata Alam Gunung Batur Bukit Payang adalah 1) motivasi untuk mendapatkan suasana yang berbeda, 2) melakukan suatu hal yang baru dan berbeda seperti: trekking mountain, dan 3) motivasi untuk membuat pikiran menjadi tenang dan santai dengan melihat pemandangan dari puncak gunung. Dan motivasi yang menarik (pull factor) wisatawan untuk melakukan trekking mountain, diantaranya: 1) lingkungan alam di puncak Gunung Batur sangat mempesona, 2) keberadaan satwa liar di puncak gunung, dan 3) suasana dan iklim yang mendukung saat melakukan trekking di Taman Wisata Alam Gunung Batur Bukit Payang.

Sedangkan motivasi yang dianggap kurang berpengaruh bagi wisatawan saat melakukan trekking mountain di Taman Wisata Alam Gunung Batur Bukit Payang adalah melakukan trekking mountain dengan anggota keluarga untuk memperkuat hubungan kekeluargaan dan melakukan trekking mountain untuk meningkatkan gengsi atau prestise.

2. Persepsi wisatawan mancanegara terhadap trekking mountain di Taman Wisata Alam Gunung Batur Bukit Payang secara keseluruhan adalah sangat baik dengan total rata-rata keseluruhan 52,85 dan ratarata keseluruhan sebesar 4,06. Walaupun terdapat dua pernyataan yang masih memperoleh skor yang rendah mengenai kebersihan yang dirasa masih kurang, yaitu kebersihan jalur trekking yang memperoleh skor 501 dengan rata-rata 3,34 dan kebersihan toilet umum yang memperoleh skor 327 dengan rata-rata 2,18.

\section{Saran}

1. Saran bagi peneliti selanjutnya, diharapkan dapat meneliti hal lain mengenai wisatawan mancanegara, seperti: mengenai persepsi wisatawan mancanegara terhadap aktivitas trekking mountain di Taman Wisata Alam Gunung Batur Bukit Payang ataupun pengemasan paket wisata trekking yang berbeda dari paket yang telah ada saat ini.

2. Saran kepada Perhimpunan Pramuwisata Pendakian Gunung Batur adalah agar lebih: 1) meningkatkan kualitas trekking guide khususnya dalam berbahasa dan pengetahuan Taman Wisata Alam, 2) meningkatkan kebersihan jalur trekking dengan menghimbau setiap trekking guide membawa kantong plastik untuk memungut sampah plastik, 3) meningkatkan kebersihan toilet umum dengan menempatkan satu orang cleaning service di setiap toilet, 4) menjaga kelestarian 
lingkungan di Taman Wisata Alam Gunung Batur Bukit Payang sehingga tetap menjadi daya tarik utama dan faktor penarik utama wisatawan melakukan trekking, serta sebuah saran dari beberapa wisatawan agar disediakan sebuah toilet umum di jalur menuju puncak Taman Wisata Alam Gunung Batur Bukit Payang sehingga wisatawan tidak terlalu jauh mencari toilet saat pendakian.

\section{DAFTAR PUSTAKA}

Anonim. 2016. Data Jumlah Wisatawan Mancanegara Yang Melakukan Trekking Mountain. Bali: Dinas Pariwisata Kabupaten Bangli

Cahya Murti, Hestara dan Sujali. 2013. Persepsi Wisatawan Terhadap
Pengembangan Obyek Wisata Batang Dolphin Center. UGM. Jurnal Pengembangan Obyek Wisata: Vol. 2, Nomor 2, 2013

Pitana dan Gayatri. 2005. Sosiologi Pariwisata. Yogyakarta: Andi Offset

Sugiyono. 2015. Metode Penelitian Kuantitatif, Kualitatif, Dan $R \& D$. Bandung: Alfabeta

Usman, Husaini dan Akbar, Purnomo Setiady. 2006. Metodelogi Penelitian Sosial. Jakarta: Bumi Aksara

Wall, Georffrey dan Mathieson, Alister. 2006. Tourism Change, Impacts And Opportunnities. England: Pearson Education Limited. 